\title{
ALTERNATIF PENGGUNAAN KERIKIL GUNUNG PEGAT SEBAGAI BAHAN PERKERASAN JALAN RAYA
}

\author{
Rio Rahma Dhana ${ }^{1}$,Nugroho Aji Putra ${ }^{2}$ \\ 1,2 Fakultas Teknik Universitas Islam Lamongan \\ email : riorahma@yahoo.co.id; curvaboys17@gmail.com
}

\begin{abstract}
The road is one of the transportation infrastructures which is expected that the road condition has durability according to the ade of the plan. This study aims to determine in general the use of pegat mountain pebbles as highway pavement material (AC-WC). In this study using a mixture of asphalt laston type IX SNI 03-1737-1989 with variations of pegat mountain gravel mixture by 0\%, 50\%, 100\%. From the research result obtained the highest marshall stability value of $1.214 \mathrm{~kg}$, highest plastic melt (flow) of $3,40 \mathrm{~mm}$, cavity in mixture (void in the mix) increased by $4,48 \%$, cavity filled with asphalt (void filled with asphalt) highest increase of $0,83 \%$, cavity in aggregate (void in mineral aggregate) increased by $22,23 \%$, and marshall quotient (MQ) increased by $249 \%$ in the variation of pegat mountain gravel additives by $50 \%$.
\end{abstract}

Keyword: Asphalt, Road, Laston Type IX, Pegat Mountain Gravel

\section{ABSTRAK}

Jalan tersebut merupakan salah satu infrastruktur transportasi yang diharapkan kondisi jalannya memiliki daya tahan sesuai dengan rencana. Penelitian ini bertujuan untuk mengetahui secara umum penggunaan kerikil gunung pegat sebagai material perkerasan jalan raya $(A C-W C)$. Dalam penelitian ini menggunakan campuran aspal laston tipe IX SNI 03-1737-1989 dengan variasi campuran kerikil gunung pegat sebesar $0 \%, 50 \%, 100 \%$. Dari hasil penelitian diperoleh nilai stabilitas marshall tertinggi 1,214kg, lelehan plastik (aliran) 3,40mm, rongga dalam campuran (void dalam campuran) meningkat sebesar 4,48\%, rongga diisi dengan aspal (batal diisi dengan aspal)) peningkatan tertinggi 0,83\%, rongga agregat (batal pada agregat mineral) meningkat sebesar 22,23\%, dan marshall quotient (MQ) meningkat sebesar $249 \%$ dalam variasi aditif kerikil gunung pegat sebesar $50 \%$.

Kata kunci: Aspal, Jalan, Laston Tipe IX, Kerikil Gunung Pegat

\section{PENDAHULUAN}

Jalan adalah suatu prasarana perhubungan darat dalam bentuk apapun, meliputi segala bagian jalan termasuk bangunan pelengkap dan perlengkapannya yang di peruntukan bagi lalu lintas (Menurut undang -undang jalan raya no. 13 /1980) (April Gunarto, 2019). Panjang jalan di rinci menurut jenis permukaannya pada tahun 1987 untuk jalan aspal sepanjang 93.778km, jalan bukan aspal $120.998 \mathrm{~km}$, sehingga total panjang jalan aspal sepanjang $214.776 \mathrm{~km}$, sedangkan pada tahun 2012 untuk jalan aspal panjangnya $285.252 \mathrm{~km}$, jala bukan aspal sepanjang $216.717 \mathrm{~km}$, sehingga total panjang jalan tahun 2012 mencapai $501.969 \mathrm{~km}$ (kementrian pekerjaan umum dan dinas pekerjaan umum) (Zaenuri, Romadhon, Gunarto, \& Cahyono, 2018).

Lamongan merupakan salah satu daerah dengan sumber daya alam yang melimpah. Hal ini dapat ditandai dengan adanya gunung pegat yang berada di Babat Lamongan. Batu kapur dan batu kerikil gunung adalah salah satu material Gunung Pegat yang memiliki tingkat kekerasan 
yang rendah. Batu kapur dan kerikil gunung sudah banyak di manfaatkan oleh masyarakat sekitar.

\section{METODE PENELITIAN}

Diagram Alur Penelitian / Flow Chart

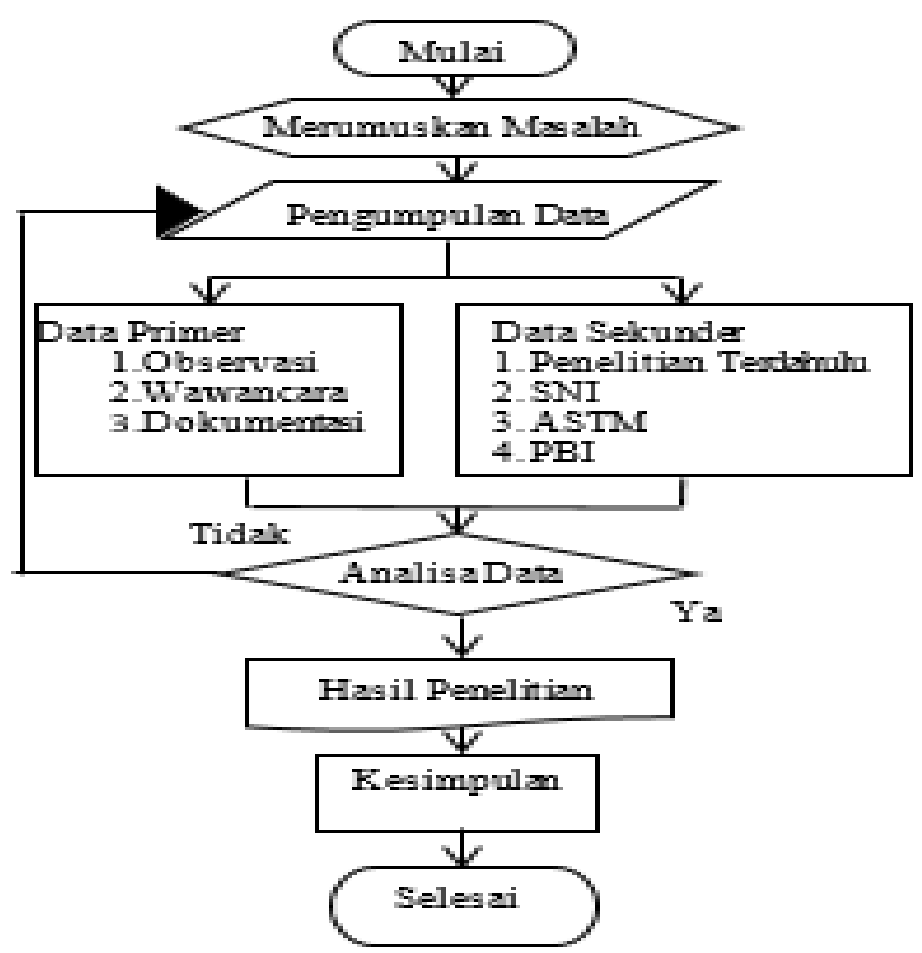

Gambar : 1 flow chart

\section{PEMBAHASAN}

\section{Hasil Pengujian Marshall Test}

Pengujian Marshall Test dilakukan bertahap sesuai dengan tujuan penelitian, yakni pertama dilakukan untuk mengetahui kadar agregat kasar yang digunakan apakah sudah memenuhi syarat dan kedua untuk mengetahui pengaruh penambahan kerikil gunung pegat kasar dalam campuran terhadap nilai-nilai Marshall Properties yaitu stabilitas Marshall (Marshall Stability), persentase Rongga Terisi Aspal (Void Filed With Asphalt / VFWA), Rongga Dalam Campuran (Void In The Mix / VIM), Rongga dalam agregat (Void In Mineral Aggregate), Kelelahan Plastis (Flow), dan Marshall Quotient (MQ).

Tabel: Pengaruh Pengantian Kerikil Gunung Pegat Terhadap Stabilitas Marshall (Marshall Stability) 


\begin{tabular}{|c|c|c|c|c|c|}
\hline \multicolumn{7}{|c|}{ Stabilitas } \\
\cline { 2 - 6 } \\
\begin{tabular}{|c|c|c|c|c|c|} 
Kadar \\
Kerikil
\end{tabular} & Stabilitas & $\begin{array}{r}\text { Penaikan / } \\
\text { Penurunan } \\
\text { Kenaikan / } \\
\text { Penurunan } \\
(\%)\end{array}$ & AASHTO & Ketentuan \\
\hline 0 & 821,00 & 0,00 & 0,00 & $550 \geq$ & Memenuhi \\
\hline 1 & 1214,00 & 393,00 & 47,87 & $550 \geq$ & Memenuhi \\
\hline 0.5 & 956,00 & 135,00 & 16,44 & $550 \geq$ & Memenuhi \\
\hline
\end{tabular}

Sumber : Hasil Penelitian, 2019

Penelusuran menggunakan model regresi menunjukkan bahwa pengantian kerikil gunung pegat dengan variasi $0 \%, 50 \%, 100 \%$ dari berat agregat kasar pada campuran, secara spesifik memperlihatkan kenaikan dan penurunan Marshall Stability.

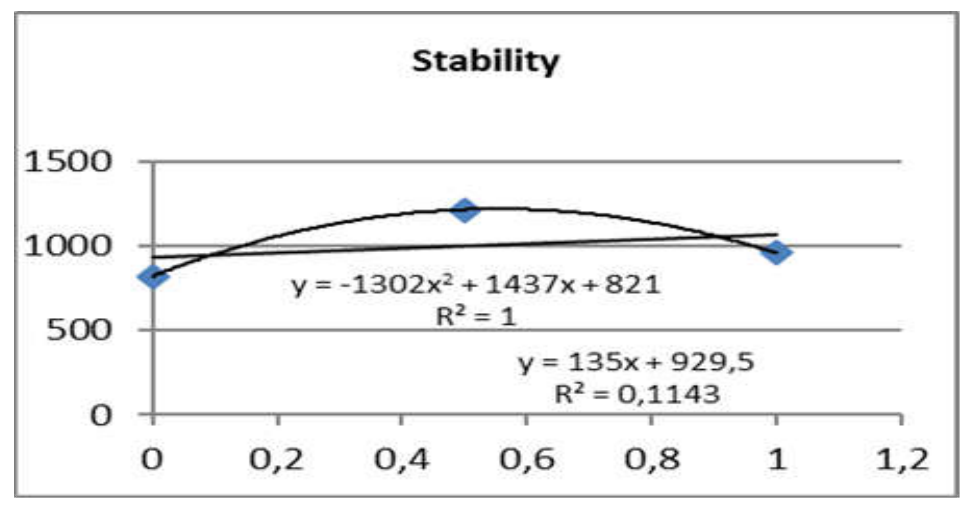

Gambar 1: Pengaruh Pengantian Kerikil Gunung Pegat Terhadap Stabilitas Marshall

Pengantian kerikil gunung pegat dengan variasi $0 \%, 50 \%, 100 \%$ dari berat agregat kasar pada campuran, secara umum memperlihatkan kenaikan nilai stabilitas seiring dengan kenaikan prasentase pengantian agregat kasar dengan kerikil gunung pegat. Nilai stabilitas tertinggi mencapai $1.214 \mathrm{Kg}$ pada pengantian kerikil gunung pegat sebesar $50 \%$.

Tabel 2: Pengaruh Subtitusi Kerikil Gunung Pegat Terhadap Rongga Dalam Campuran (Void In The Mix / VIM)

\begin{tabular}{|c|c|c|c|c|c|}
\hline \multicolumn{6}{|c|}{ Stabilitas } \\
\hline $\begin{array}{c}\text { Kadar } \\
\text { Kerikil }\end{array}$ & Stabilitas & $\begin{array}{c}\text { Kenaikan / } \\
\text { Penurunan }\end{array}$ & $\begin{array}{c}\text { Prosen } \\
\text { Kenaikan / } \\
\text { Penurunan } \\
(\%)\end{array}$ & AASHTO & Ketentuan \\
\hline 0 & 821,00 & 0,00 & 0,00 & $550 \geq$ & Memenuhi \\
\hline 0.5 & 1214,00 & 393,00 & 47,87 & $550 \geq$ & Memenuhi \\
\hline 1 & 956,00 & 135,00 & 16,44 & $550 \geq$ & Memenuhi \\
\hline
\end{tabular}

Sumber : Hasil Penelitian, 2019 
Penelusuran menggunakan model regresi menunjukkan bahwa pengantian kerikil gunung pegat dengan variasi $0 \%, 50 \%, 100 \%$ dari berat agregat kasar pada campuran, secara spesifik memperlihatkan kenaikan dan penurunan VIM.

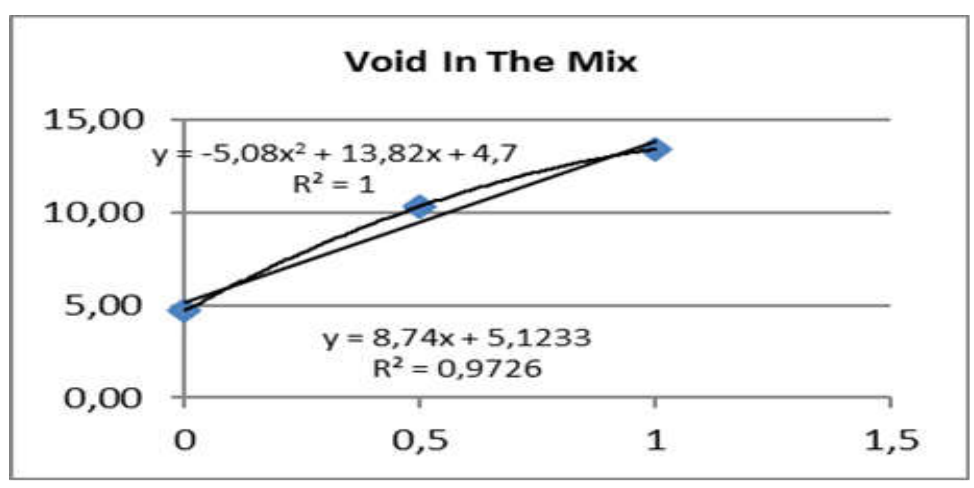

Sumber : Hasil Penelitian, 2019

Gambar 2: Pengaruh Subtitusi Kerikil Gunung Pegat Terhadap Rongga Dalam Campuran (Void In The Mix / VIM)

Berdasarkan gambar diatas titik puncak atau extreme point VIM terdapat pada variasi pergantian kerikil gunung pegat sebesar 50\% dari berat agregat kasar pada campuran dengan nilai VIM sebesar $4,77 \%$

Tabel 3: Pengaruh Subtitusi Kerikil Gunung Pegat Terhadap Rongga Dalam Agregat (Void In Mineral Aggregate / VMA)

\begin{tabular}{|c|c|c|c|c|c|}
\hline \multicolumn{6}{|c|}{ VMA } \\
\hline $\begin{array}{c}\text { Kadar } \\
\text { Kerikil }\end{array}$ & VMA & $\begin{array}{c}\text { Kenaikan / } \\
\text { Penurunan }\end{array}$ & $\begin{array}{c}\text { Prosen } \\
\text { Kenaikan / } \\
\text { Penurunan } \\
(\%)\end{array}$ & $\begin{array}{c}\text { AASHT } \\
\text { O }\end{array}$ & Ketentuan \\
\hline 0 & 14.49 & 0,00 & 0,00 & $11-23$ & Memenuhi \\
\hline 0.5 & 19.56 & 5.07 & 34.99 & $11-23$ & Memenuhi \\
\hline 1 & 22.23 & 7.74 & 53.42 & $11-23$ & Memenuhi \\
\hline
\end{tabular}

Sumber : Hasil Penelitian, 2019

Penelusuran menggunakan model regresi menunjukkan bahwa pengantian kerikil gunung pegat dengan variasi $0 \%, 50 \%, 100 \%$ dari berat agregat kasar pada campuran, secara spesifik memperlihatkan kenaikan dan penurunan $V M A$.

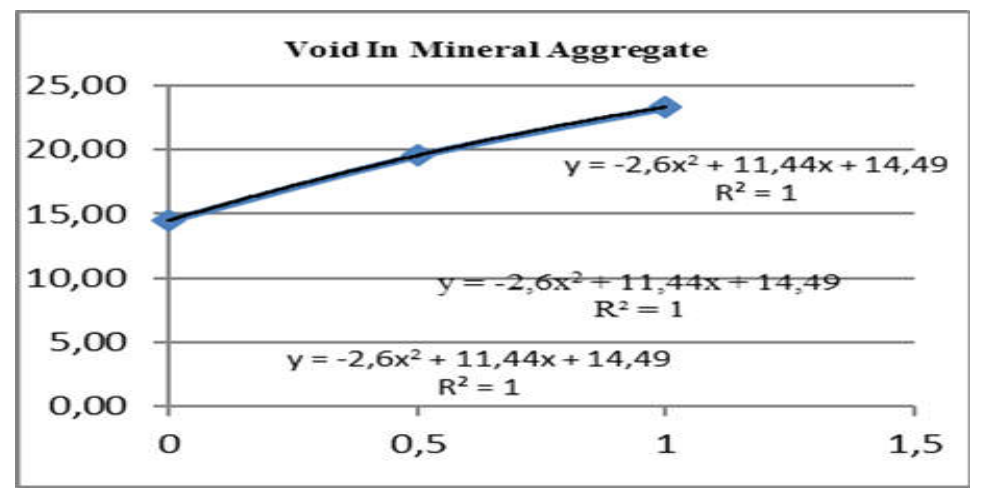


Sumber : Hasil Penelitian, 2019

\section{Gambar 3: Pengaruh Subtitusi Kerikil Gunung Pegat Terhadap Rongga Dalam Agregat}

(Void In Mineral Aggregate/VMA)

Berdasarkan gambar diatas titik puncak atau extreme point Marshall Stability terdapat pada variasi pengantian kerikil gunung pegat sebesar $100 \%$ dari berat agregat kasar pada campuran dengan nilai Marshall Stability sebesar $53.42 \%$.

Tabel 4: Pengaruh Subtitusi Kerikil Gunung Pegat Terhadap Rongga Terisi Aspal (Void Filled With Asphalt / VFWA)

\begin{tabular}{|c|c|c|c|c|c|}
\hline \multicolumn{7}{|c|}{ VFWA } \\
\hline $\begin{array}{c}\text { Kadar } \\
\text { Kerikil }\end{array}$ & VFWA & $\begin{array}{c}\text { Kenaikan / } \\
\text { Penurunan }\end{array}$ & $\begin{array}{c}\text { Prosen } \\
\text { Kenaikan / } \\
\text { Penurunan } \\
(\%)\end{array}$ & $\begin{array}{c}\text { AASHT } \\
\text { O }\end{array}$ & Ketentuan \\
\hline 0 & 99.03 & 0,00 & 0,00 & $65-100$ & Memenuhi \\
\hline 0.5 & 68.83 & -30.20 & -30.50 & $65-100$ & Memenuhi \\
\hline 1 & 58.21 & -40.82 & -41.22 & $65-100$ & Memenuhi \\
\hline
\end{tabular}

Sumber : Hasil Penelitian, 2019

Penelusuran menggunakan model regresi menunjukkan bahwa subtitusi kerikil gunung pegat dengan variasi $0 \%, 50 \%$, dan $100 \%$ dari berat agregat halus pada campuran, secara spesifik memperlihatkan penurunan dan kenaikan $V F W A$.

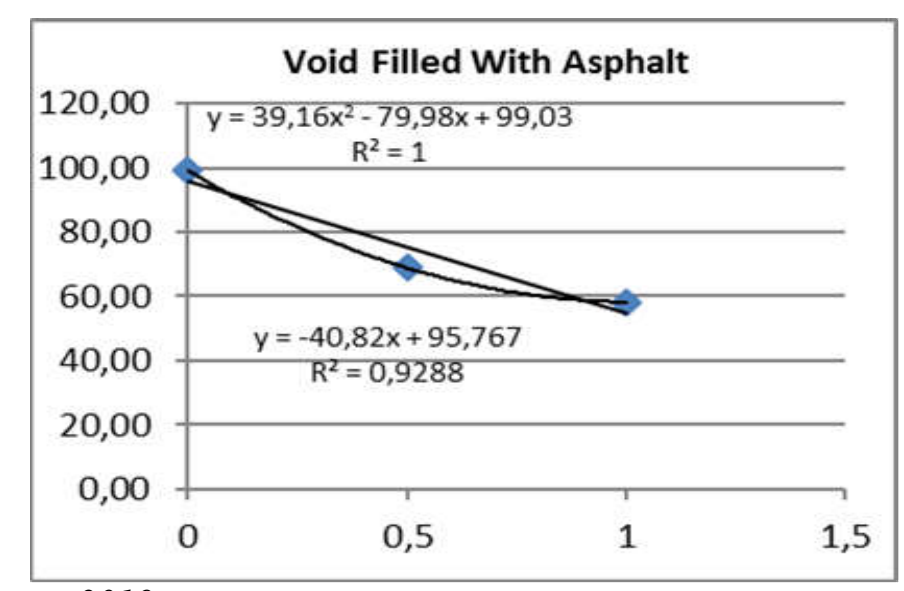

Sumber : Hasil Penelitian, 2019

Gambar 4: Pengaruh Subtitusi Kerikil Gunung Pegat Terhadap Rongga Terisi Aspal (Void Filled With Asphalt/VFWA) 
Berdasarkan gambar diatas titik puncak atau extreme point VFWA terdapat pada variasi kerikil gunung pegat sebesar $100 \%$ dari berat aspal pada campuran dengan nilai $V F W A$ sebesar $41.22 \%$.

Tabel 5 Pengaruh Subtitusi Kerikil Gunung Pegat Terhadap Kelelehan Plastis (Flow)

Sumber : Hasil Penelitian, 2019

\begin{tabular}{|c|c|c|c|c|c|}
\hline \multicolumn{6}{|c|}{ Flow } \\
\hline $\begin{array}{c}\text { Kadar } \\
\text { Kerikil }\end{array}$ & Flow & $\begin{array}{c}\text { Kenaikan / } \\
\text { Penurunan }\end{array}$ & $\begin{array}{c}\text { Prosen } \\
\text { Kenaikan / } \\
\text { Penurunan } \\
(\%)\end{array}$ & AASHTO & Ketentuan \\
\hline 0 & 2.20 & 0,00 & 0,00 & $2-4$ & Memenuhi \\
\hline 50 & 2.67 & 0.47 & 21.36 & $2-4$ & Memenuhi \\
\hline 100 & 3.40 & 1.20 & 54.55 & $2-4$ & Memenuhi \\
\hline
\end{tabular}

Penelusuran menggunakan model regresi menunjukkan bahwa subtitusi kerikil gunung pegat dengan variasi $0 \%, 50 \%$, dan $100 \%$ dari berat agregat kasar pada campuran, secara spesifik memperlihatkan kenaikan dan penurunan Flow.

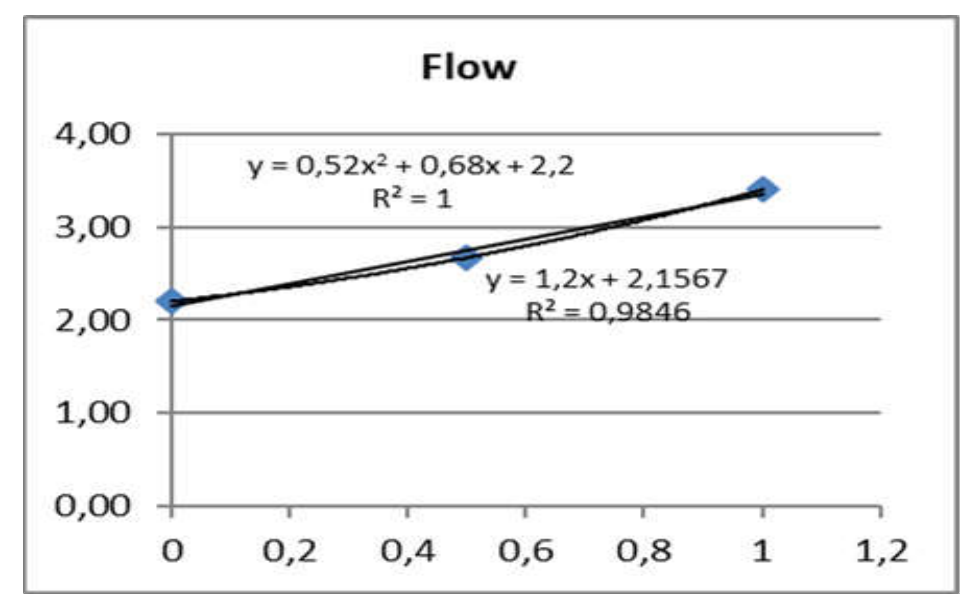

Sumber : Hasil Penelitian, 2019

Gambar 5 Pengaruh Subtitusi Kerikil Gunung Pegat Terhadap Kelelehan Plastis (Flow)

Berdasarkan gambar diatas titik puncak atau extreme point Flow terdapat pada variasi subtitusi kerikil gunung pegat sebesar $100 \%$ dari berat agregat halus pada campuran dengan nilai Flow sebesar 3,31 mm. 
Tabel 6: Pengaruh Subtitusi Kerikil Gunung Pegat Marshall Quotient (MQ)

\begin{tabular}{|c|c|c|c|c|c|}
\hline \multicolumn{7}{|c|}{ MQ } \\
\hline $\begin{array}{c}\text { Kadar } \\
\text { Kerikil }\end{array}$ & MQ & $\begin{array}{c}\text { Kenaikan / } \\
\text { Penurunan }\end{array}$ & $\begin{array}{c}\text { Prosen } \\
\text { Kenaikan / } \\
\text { Penurunan } \\
(\%)\end{array}$ & AASHTO & Ketentuan \\
\hline 0 & 380.06 & 0,00 & 0,00 & $200-350$ & Tidak \\
\hline 50 & 458.32 & 78.26 & 20.59 & $200-350$ & Tidak \\
\hline 100 & 288.71 & -91.35 & -24.04 & $200-350$ & Memenuhi \\
\hline
\end{tabular}

Sumber : Hasil Penelitian, 2019

Penelusuran menggunakan model regresi menunjukan bahwa subtitusi krikil gunung pegat dengan variasi $0 \%, 50 \%$ dan $100 \%$ dari berat agregat kasar pada campuran secara spesifik memperlihatkan kenaikan dan penurunan Marshall Quotient.

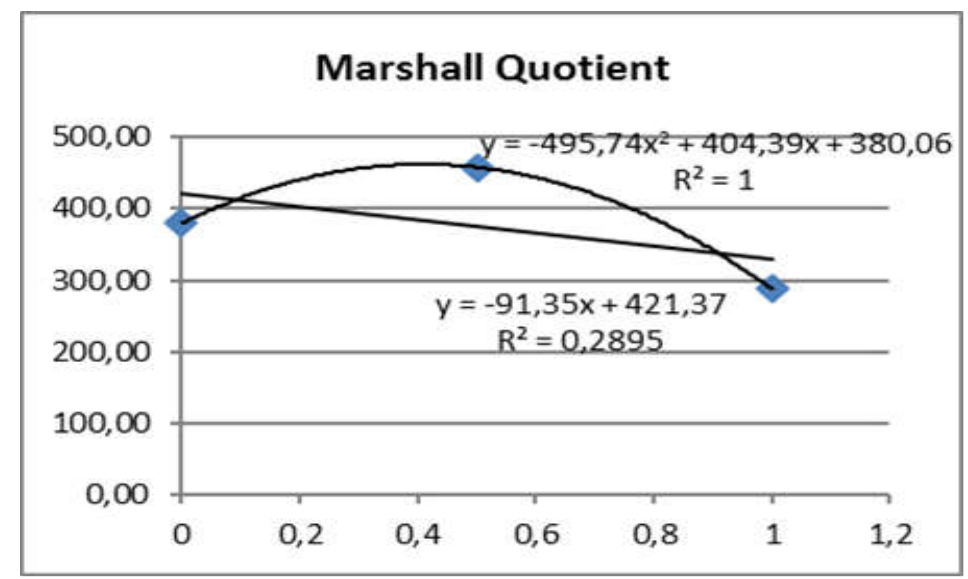

Sumber : Hasil Penelitian, 2019

Gambar 6: Pengaruh Subtitusi Kerikil Gunung Pegat Marshall Quotient (MQ)

Berdasarkan gambar diatas titik puncak atau extreme point $M Q$ terdapat pada variasi kerikil gunung pegat sebesar $100 \%$ dari berat agregat kasar pada campuran dengan nilai $M Q$ sebesar $249,01 \mathrm{~kg} / \mathrm{mm}$.

\section{KESIMPULAN DAN SARAN}

\section{Kesimpulan}

Berdasarkan penelitian yang telah dilakukan tentang pengaruh penggunaan kerikil gunung pegat sebagai bahan pengganti agregat kasar pada campuran Laston type IX SNI 03 - 1737 1989 dapat disimpulkan sebagai berikut 
1. Setelah melalui proses pengolahan yang benar kerikil gunung pegat sampai menjadi agregat kasar, kerikil gunung pegat dapat digunakan sebagai bahan tambah campuran aspal panas campuran Laston Tipe IX SNI 03-1737-1989.

2. Subtitusi variasi kerikil gunung pegat $0 \%, 50 \%, 100 \%$ dari berat agregat kasar pada penelitian ini menunjukkan nilai Marshall Properties yang paling ideal dihitung dengan menggunakan persamaan model regresi dengan indeks determinasi paling tinggi dimana pada persamaan model tersebut didapatkan nilai indeks determinasi $\left(\mathrm{R}^{2}\right)=1$ untuk Marshall properties yang paling tinggi adalah subtitusi kerikil gunung pegat $100 \%$ dengan parameter marshall yang meliputi : Stability 1214kg, VIM 4,84\%, VMA 22,23\%, VFWA 58,21\%, Flow 3,40 mm, Marshall Question 249,1\%. Dari hasil tersebut subtitusi kerikil gunung pegat dengan kadar 100\% tidak memenuhi kriteria dalam standar nasional indonesia.

\section{Saran}

1. Pelaksanaan penelitian memerlukan tenaga-tenaga yang berpengalaman, mempunyai ketelitian yang cukup serta peralatan yang baik dan sesuai standart indonesia sehingga validitas data yang dihasilkan lebih baik.

2. Mahasiswa agar lebih terampil, kreatif, dan profesional sehingga memperoleh pengetahuan yang dapat dijadikan sebagai bekal pada masa yang akan datang

\section{Daftar Pustaka}

[1] AASHTO T85-88. Metode Pengujian Berat Jenis Dan Penyerpan Air Agregat Halus.

[2] American Society for Testing and Material 1989 (ASTM d-1559), Karakteristik Marshall.

[3] Anonim 2017, Modul Perencanaan Mix Design (Perencanaan Campuran Beraspal). Laboratorium Rekayasa Jalan.Departemen Teknik Sipil Universitas islam Lamongan. Lamongan.

[4] April Gunarto, A. I. C. K. (2019). Penelitian Campuran Aspal Beton Dengan Menggunakan Filler Bunga Pinus. UKaRsT, 3(1), 37. https://doi.org/10.30737/ukarst.v3i1.351

[5] Bina Marga 2010, "Spesifikasi Umum 2010 Divisi 6 Revisi 3 seksi 6 perkerasan Beraspal". Jakarta : Direktorat Jendral Bina Marga.

[6] Bina Marga 2010, “Spesifikasi Umum 2010 Revisi 2”.Jakarta : Direktorat Jendral Bina Marga.

[7] Departemen Pemukiman Dan Pengembangan Wilayah 2013, “Pembagian Lapisan Laston”, Jakarta.

[8] Nofrianto, 2014, "Kajian Campuran Panas Aspal Aggregat Asbuton Retona Blend 55 (Ac-Wc) Dan Aspal Pen 60/70 Dengan Pengujian Marshall”, Jurusan Teknik Sipil, Fakultas Teknik Sipil dan Perencanaan Institut Teknologi Padang, Padang. 
[9] SNI 06-2489-1991. “Metode Pengujian Campuran Aspal Dengan Alat Marshall”, Jakarta: BSN.

[10] Sukirman, S., 1992. "Perkerasaan Lentur Jalan Raya", Bandung.

[11] Zaenuri, M., Romadhon, R., Gunarto, A., \& Cahyono, A. (2018). PENELITIAN PENGGUNAAN BATU GAMPING SEBAGAI AGREGAT KASAR DAN FILLER PADA ASPAL CAMPURAN AC-BC. UKaRsT, 2(1), 24-35.

[12] Badan Standarisasi Nasional, BSSNI,2011. SKSNI 2434-2011. Tentang Cara Uji Titik Lembek Aspal Dengan Alat Cincin Dan Bola (Ring And Ball)

[13] Ahmad Bagir dan Gigih Eka Pradana., 2011.Pemanfaatan Serat Eceng Gondok

[14] Badan Standarisasi Nasional, 2012. SNI ASTM C136:2012 : Metode uji untuk analisis saringan agregat halus dan agregat kasar. Jakarta: BSN.

[15] Badan Standarisasi Nasional, SNI 8129:2015 tentang Spesifikasi Stone Matrix Asphalt (SMA)

[16] Badan Standarisasi Nasional, SNI 03-6388,2000, Spesifikasi Agregat Lapis Pondasi Bawah Lapis Pondasi Atas Dan Lapis Permukaan 